\title{
Acute and Chronic Effects of 3-4, Methylenedioxymethamphetamine on Pyramidal Cells of Hippocampus
}

\author{
Mohamad Bakhtiar Hesam Shariati ${ }^{1,2}$; Fatemeh Mirzaei $^{2}$; Sara Soleimani Asl ${ }^{1,2}$; Leila Mosavi $^{3}$; \\ Maryam Sohrabi ${ }^{2, *}$ \\ ${ }_{1}^{1}$ Research Center for Behavioral Disorders and Substance Abuse, Hamadan University of Medical Sciences, Hamadan, IR Iran \\ ${ }^{2}$ Department of Anatomy, Hamadan University of Medical Sciences, Hamadan, IR Iran \\ ${ }^{3}$ Department of Pathology, Hamadan University of Medical Sciences, Hamadan, IR Iran \\ ${ }^{*}$ Corresponding author: Maryam Sohrabi, Department of Anatomy, School of Medicine, Hamadan University of Medical Sciences, Hamadan, IR Iran. Tel/Fax: +98-8118380208, E-mail: \\ sohrabi3@yahoo.com
}

Received: July 6, 2014; Revised: September 2, 2014; Accepted: September 3, 2014

\begin{abstract}
Background: Ecstasy or 3-4, methylenedioxymethamphetamine (MDMA), as an amphetamine derivate, could lead to learning and memory impairment.

Objectives: As the hippocampus is responsible for learning and memory, herein we evaluated acute and chronic effects of MDMA on the structure of the hippocampus.

Materials and Methods: Male Wistar rats (200-250 g) received single or multiple injections of MDMA (10 mg/kg, IP). At the end of the study, rats were killed and their brains were removed. Hippocampus sections were prepared to study the structure of hippocampus CA1. Data was analyzed using SPSS 16 software and one-way analysis of variance test.

Results: Our findings showed that cell density decreased in MDMA-treated groups in comparison to the intact group. Administration of multiple doses of MDMA significantly decreased the cell number when compared with intact $(\mathrm{P}<0.001)$ and acute $(\mathrm{P}<0.01)$ groups. Conclusions: These data suggest that MDMA treatment caused cell death in CA1, which was more extensive in the chronic treatment group.
\end{abstract}

Keywords:Methylenedioxymethamphetamine; Hippocampus; Cell Death

\section{Background}

Ecstasy or $3-4$, methylenedioxymethamphetamine (MDMA), is a substituted amphetamine with very high abuse liability in the world (1). It is a widely abused drug, especially among adolescents and young adults. According to the United Nations, in 2009 the worldwide prevalence of MDMA use ranged from 11 to 28 million individuals who were between the ages of 5 and 64 years (2). Moreover, MDMA leads to elevated mood, feeling of closeness towards others and a desire to touch others. After-effects can be sleep problems, anxiety and depression (3). It has been reported that repeated use of ecstasy produces long-term neurotoxicity in humans and primates $(4,5)$. It can induce pathological cerebrovascular responses (6) and affect the immune system (7). In addition, MDMA can produce both irreversible and reversible brain changes, such as expression of microglia cells and hypertrophy of astrocytes, and neuronal degeneration in various areas of the brain (8). Some studies have reported that ecstasy has neurotoxic effects on serotonergic, dopaminergic and adrenergic endings (9). It causes acute release of serotonin from nerve endings, binds to the serotonin transporter (SERT), and inhibits serotonin reuptake, which leads to serotonin reduction and memory impairment $(8,10)$. In a previous study, we showed that acute and chronic administration of MDMA induced deficits in passive avoidance and Morris water maze tasks that were more exaggerated in acutetreated rats (11). In another study, MDMA treatment caused a decrease in novel object recognition and anxiety in the elevated plus maze (12). It has been reported that different doses of MDMA impaired locomotor activity and allocentric learning, dose dependently and acutely in rats (13).

\section{Objectives}

Since MDMA decreases serotonin in the hippocampus and causes memory impairment, and because the hippocampus is an important structure that involves spatial memory, the main objective of this study was to elucidate the effects of acute and chronic dosages of MDMA on the structure of the CA1 area of the hippocampus.

\section{Materials and Methods}

\subsection{Animals}

Fifteen male Wistar rats (weighting 200-250 g) were obtained from the animal house of Hamadan University of

Copyright (C) 2014, Hamadan University of Medical Sciences; Published by Hamadan University of Medical Sciences. This is an open-access article distributed under the terms of the Creative Commons Attribution-NonCommercial 4.0 International License (http://creativecommons.org/licenses/by-nc/4.0/) which permits copy and redistribute the material just in noncommercial usages, provided the original work is properly cited. 
Medical Sciences (Hamadan, Iran) and kept in a colony room at a temperature of $21 \pm 1^{\circ} \mathrm{C}$ ( $50 \pm 10 \%$ humidity) on a 12-hour light-dark cycle with access to water and food ad libitum. All experiments were approved by the Ethical Committee of Hamadan University of Medical Sciences.

\subsection{Treatment Groups and Drug Administration}

The rats were randomly classified into three groups $(\mathrm{n}=$ 5 per group), as follows:

1- The control or intact group was left undisrupted.

2- Acute MDMA group received intraperitoneal (IP) injection of $10 \mathrm{mg} / \mathrm{kg}$ MDMA once.

3- Chronic MDMA group received IP injection of $10 \mathrm{mg} /$ $\mathrm{kg}$ MDMA during the weekend for three weeks $(1,2,8,9$, 15, 16 days).

Body weight was recorded on first and last days of drug administration.

\subsection{Tissue Preparation for Cresyl Violet (Nissl) Staining and Histological Study}

The day after the last administration, rats from each group were deeply anesthetized with ketamine (100 mg/ $\mathrm{kg}$ ) and xylazine $(10 \mathrm{mg} / \mathrm{kg})$ and transcardially perfused with a mixture of $4 \%$ paraformaldehyde in phosphate buffer $(0.1 \mathrm{~mol} / \mathrm{L})$. Next, brains were removed from the skulls and post-fixed in the same fixation solution. The brains were dehydrated in ethanol, cleared in xylene, and embedded in paraffin. Furthermore, $10 \mu \mathrm{m}$ coronal sections from bregma: $1.34 \mathrm{~mm}$ to bregma: $-2.54 \mathrm{~mm}$ were prepared by a microtome (Leica, IL, USA). The sections were then deparaffinized, rehydrated, and stained by $0.1 \%$ cresyl violet solution (Nissl stain). The pyramidal intact cells of CA1 with defined cell bodies and nuclei were counted using a light microscope (Olympus Provis, Ax70, Japan) attached to a digital camera (Olympus, DP 11, Japan). For each animal, the average neuronal counts were obtained by counting five serial sections at $400 \times$ magnification.

\subsection{Statistical Analysis}

Statistical analyses were performed by the SPSS 16 software. Analyses of cell density and body temperature were performed using one-way and two-way repeated mea- surement analysis of variance (ANOVA), respectively. All results were expressed as mean \pm SEM. Values of $\mathrm{P}<0.05$ were considered significant.

\section{Results}

\subsection{Effect of MDMA on Body Weight}

For the body weight, the intact and acute groups did not perform different, thus we considered them as one. As shown in Figure 1, repeated administration of MDMA caused a reduction in body weight when compared to the intact group, but this was not significant.

\subsection{Effect of MDMA on Cell Density in CA1 Hippo- campus}

Figure 2 A-C shows coronal sections of cells in the CA1 hippocampus. Light microscopy of the sections stained with Nissl stain showed that pyramidal intact cells had defined cell bodies and nuclei. Administration of MDMA caused neuronal cell death and dark neuron formation. As shown in Figure 2 B and C, dark neurons were characterized by neuronal shrinkage, cytoplasm hyperstainability, and nuclear pyknosis. Analysis of variance of cell count showed that MDMA reduced neural density in the CA1 hippocampus compared to the intact group. Administration of multiple doses of MDMA significantly led to cell loss when compared with intact $(\mathrm{P}<0.001)$ and acute $(\mathrm{P}<0.01)$ groups (Figure 3$)$.

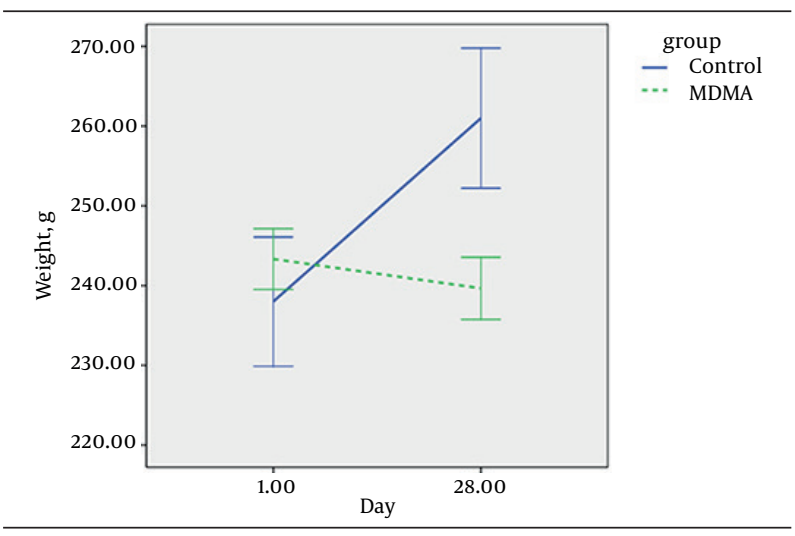

Figure 1. The Body Weight of Animal in Intact and MDMA-Treated Groups

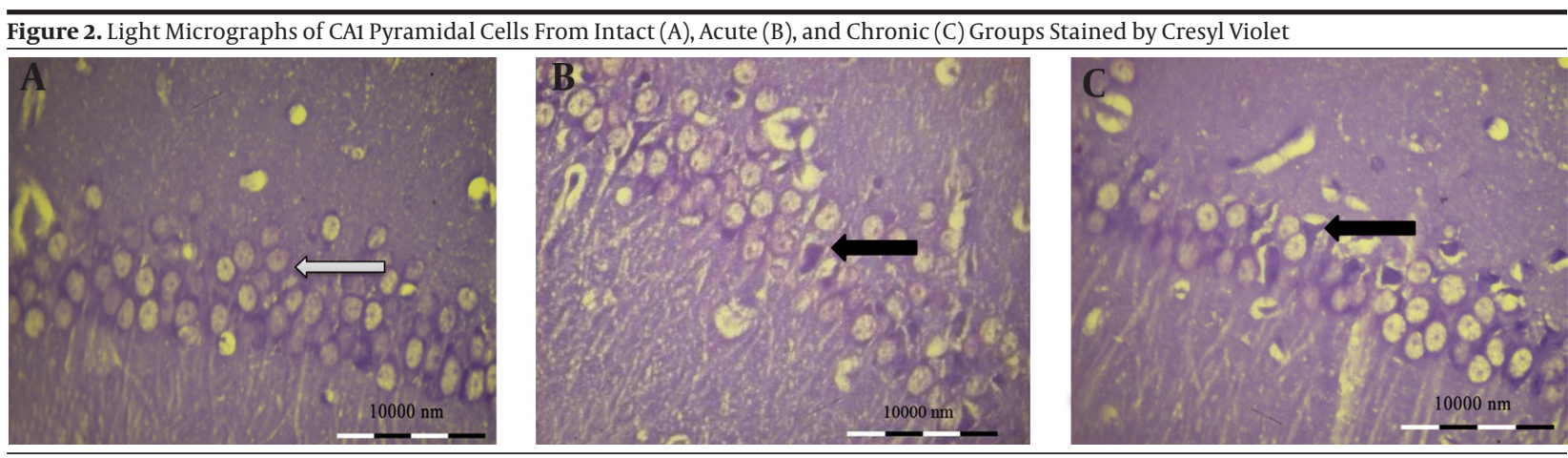

The white arrow shows an intact neuron. The black arrows show dark cells. 
Figure 3. Mean and Standard Deviation of Neural Density in the CA1 Region

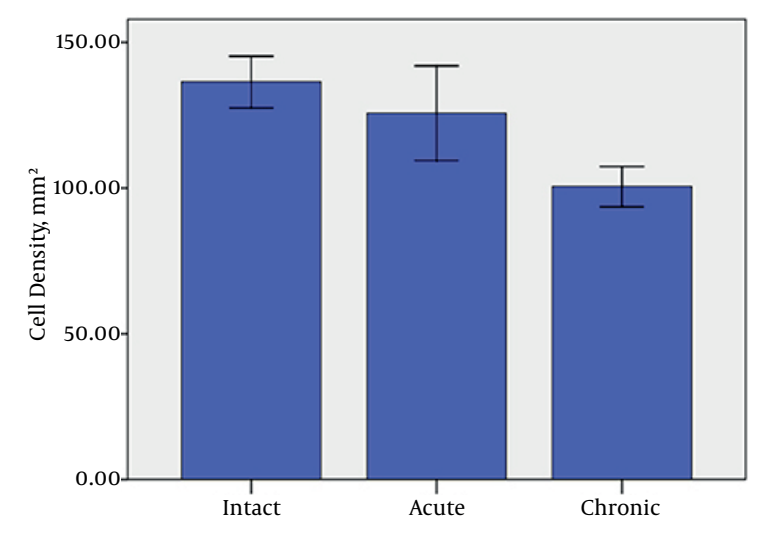

A) $\mathrm{P}<0.001$ vs. intact group, B) $\mathrm{P}<0.01$ vs. acute group.

\section{Discussion}

The brain is sensitive to toxic agents because of low antioxidant and cell membrane lipids (14). As mentioned above, MDMA treatment can impair learning and memory (15). It has been reported that MDMA treatment leads to reduction in preference for the target quadrant in the Morris water maze (16) and impairment of retention in passive avoidance tasks (17). Moreover, MDMA decreases 5-HT levels in the amygdala, hippocampus, and striatum that involve learning and memory $(12,18)$ and are susceptible to 5-HT neurotoxicity following MDMA treatment (19). The results of this study showed that MDMA causes cell loss in the CA1 hippocampus. The other finding was that the MDMA-induced toxicity in chronic-treated rats was more exaggerated than acute-treated rats. Consistent with our study, Riezzo et al. showed that MDMA administration in rats caused cell death in the CA1 hippocampus (20). Furthermore, Kermanian et al. reported an increase in dark cells in the hippocampus following MDMA administration (21). Administration of MDMA causes rapid intracellular $\mathrm{Ca}^{2+}$ influx, mitochondrial membrane depolarization and reactive oxygen species (ROS) production (22). It also causes oxidative stress, ROS generation (20) and glutathione (GSH) depletion (23) that lead to neurotoxic effects. It has been shown that GSH depletion causes spatial memory impairment (24). Glutathione has excitatory effects on the serotonergic system and modulatory effects on long term potentiation in the hippocampus (25). Furthermore, GSH plays an important role in maintaining homeostasis and protects cells against oxidative and toxic factors, and DNA damage (26). Following administration, MDMA is converted to N-methyl-a-methyl dopamine (MeDA) via the isoenzyme, cytochrome p-450, catabolism that is metabolized in the presence of NADPH into quinine, which reacts with glutathione, subsequently generating ROS $(27,28)$. Taken together, it seems that MDMA treatment causes glutathione depletion and ROS production that lead to cell death.

In conclusion, our results showed that the acute and chronic administration of MDMA induces cell death in CA1 hippocampus. Toxicity was exaggerated in chronic treated rats and this needs to be investigated further.

\section{Acknowledgements}

The authors would like to thank the staff of the embryology laboratory, Hamadan University of Medical Sciences, Hamadan, Iran.

\section{Funding/Support}

The data used in this paper was extracted from the MSc thesis of M.B. Hesam Shariati. This project was supported financially by Hamadan University of Medical Sciences No.9206262025.

\section{References}

1. Morgan MJ. Ecstasy(MDMA): a review of its possible persistent psychological effects. Psychopharmacology (Berl). 2000;152(3):230-48.

2. United Nations Office on Drugs and Crime . World Drug Report 2011. New York: United Nations; 2011.

3. Bhattachary S, Powell JH. Recreational use of 3,4-methylenedioxymethamphetamine (MDMA) or 'ecstasy': evidence for cognitive impairment. Psychol Med.2001;31(4):647-58.

4. Breivik T, Bogen IL, Haug KH, Fonnum F, Opstad PK, Eide DM, et al. Effects of long-term exposure of 3,4-methylenedioxymethamphetamine (MDMA; "ecstasy") on neuronal transmitter transport, brain immuno-regulatory systems and progression of experimental periodontitis in rats. Neurochem Int. 2014;72:30-6.

5. Schindler CW, Thorndike EB, Blough BE, Tella SR, Goldberg SR, Baumann MH. Effects of 3,4-methylenedioxymethamphetamine (MDMA) and its main metabolites on cardiovascular function in conscious rats. BrJ Pharmacol. 2014;171(1):83-91.

6. Quate L, McBean DE, Ritchie IM, Olverman HJ, Kelly PA. Acute methylenedioxymethamphetamine administration: effects on local cerebral blood flow and glucose utilisation in the Dark Agouti rat. Psychopharmacology (Berl). 2004;173(3-4):287-95.

7. Parrott AC, Buchanan T, Scholey AB, Heffernan T, Ling J, Rodgers J. Ecstasy/MDMA attributed problems reported by novice, moderate and heavy recreational users. Hum Psychopharmacol. 2002;17(6):309-12.

8. Sarkar S, Schmued L. Neurotoxicity of ecstasy (MDMA): an overview. Curr Pharm Biotechnol. 2010;11(5):460-9.

9. Elliott JM, Beveridge TJ. Psychostimulants and monoamine transporters: upsetting the balance. Curr Opin Pharmacol. 2005;5(1):94-100.

10. Soleimani Asl S, Farhadi MH, Naghdi N, Choopani S, Samzadeh Kermani A, Mehdizadeh M. Non-acute effects of different doses of 3, 4-methylenedioxymethamphetamine on spatial memory in the Morris water maze in Sprague-Dawley male rats. Neural Regener Res. 2011;6(22):1715-9.

11. Shariati H, Bakhtiar M, Sohrabi M, Shahidi S, Nikkhah A, Mirzaei F, et al. Acute effects of ecstasy on memory are more extensive than chronic effects. Basic Clin Neurosci . 2014;5(3):225-30.

12. Gurtman CG, Morley KC, Li KM, Hunt GE, McGregor IS. Increased anxiety in rats after 3,4-methylenedioxymethamphetamine: association with serotonin depletion. Eur J Pharmacol. 2002;446(13):89-96.

13. Vorhees CV, Schaefer TL, Skelton MR, Grace CE, Herring NR, Williams MT. (+/-)3,4-Methylenedioxymethamphetamine (MDMA) dose-dependently impairs spatial learning in the morris water maze after exposure of rats to different five-day intervals from birth to postnatal day twenty. Dev Neurosci. 2009;31(1-2):107-20.

14. Viegas CM, Tonin AM, Zanatta A, Seminotti B, Busanello EN, Fer 
nandes CG, et al. Impairment of brain redox homeostasis caused by the major metabolites accumulating in hyperornithinemiahyperammonemia-homocitrullinuria syndrome in vivo. Metab Brain Dis. 2012;27(4):521-30.

15. Abad S, Fole A, del Olmo N, Pubill D, Pallas M, Junyent F, et al MDMA enhances hippocampal-dependent learning and memory under restrictive conditions, and modifies hippocampal spine density. Psychopharmacology (Berl). 2014;231(5):863-74.

16. Sprague JE, Preston AS, Leifheit M, Woodside B. Hippocampal serotonergic damage induced by MDMA (ecstasy): effects on spatial learning. Physiol Behav. 2003;79(2):281-7.

17. Barrionuevo M, Aguirre N, Del Rio JD, Lasheras B. Serotonergic deficits and impaired passive-avoidance learning in rats by MDEA: a comparison with MDMA. Pharmacol Biochem Behav. 2000;65(2):233-40.

18. Morris RG, Garrud P, Rawlins JN, O'Keefe J. Place navigation impaired in rats with hippocampal lesions. Nature. 1982; 297(5868):681-3.

19. Sprague JE, Everman SL, Nichols DE. An integrated hypothesis for the serotonergic axonal loss induced by 3,4-methylenedioxymethamphetamine. Neurotoxicology. 1998;19(3):427-41.

20. Riezzo I, Cerretani D, Fiore C, Bello S, Centini F, D'Errico S, et al. Enzymatic-nonenzymatic cellular antioxidant defense systems response and immunohistochemical detection of MDMA, VMAT2, HSP70, and apoptosis as biomarkers for MDMA (Ecstasy) neurotoxicity. J Neurosci Res. 2010;88(4):905-16.

21. Kermanian F, Mehdizadeh M, Soleimani M, Ebrahimzadeh Bideskan AR, Asadi-Shekaari M, Kheradmand H, et al. The role of ade- nosine receptor agonist and antagonist on Hippocampal MDMA detrimental effects; a structural and behavioral study. Metab Brain Dis. 2012;27(4):459-69.

22. Montgomery T, Sitte H, McBean G. 4-Methylthioamphetamine (4-MTA) induces mitochondrial-dependent apoptosis in SH-SY5Y cells independently of dopamine and noradrenaline transporters. Bio Med Central Pharmacol. 2010;10(Suppl 1).

23. Montiel-Duarte C, Ansorena E, Lopez-Zabalza MJ, Cenarruzabeitia E, Iraburu MJ. Role of reactive oxygen species, glutathione and NF-kappaB in apoptosis induced by 3,4-methylenedioxymethamphetamine ("Ecstasy") on hepatic stellate cells. Biochem Pharmacol. 2004;67(6):1025-33.

24. Fernandes RS, Cotter TG. Apoptosis or necrosis: intracellular levels of glutathione influence mode of cell death. Biochem Pharmacol.1994;48(4):675-81.

25. Slivka A, Mytilineou C, Cohen G. Histochemical evaluation of glutathione in brain. Brain Res. 1987;409(2):275-84.

26. Atkuri KR, Cowan TM, Kwan T, Ng A, Herzenberg LA, Herzenberg LA, et al. Inherited disorders affecting mitochondrial function are associated with glutathione deficiency and hypocitrullinemia. Proc Natl Acad Sci U S A. 2009;106(10):3941-5.

27. Capela JP, Carmo H, Remiao F, Bastos ML, Meisel A, Carvalho F. Molecular and cellular mechanisms of ecstasy-induced neurotoxicity: an overview. Mol Neurobiol. 2009;39(3):210-71.

28. Yamamoto BK, Raudensky J. The role of oxidative stress, metabolic compromise, and inflammation in neuronal injury produced by amphetamine-related drugs of abuse. J Neuroimmune Pharmacol. 2008;3(4):203-17. 